\title{
Entanglement as a Hermeneutic Tool for Interpreting Humanities Texts: The Case of Oedipus the King and The Book of Job
}

\author{
Ronald Glasberg \\ Department of Communication, \\ Media and Film, The University of Calgary, \\ 2500 University Drive NW, Calgary, \\ Alberta, Canada $\mathrm{T}_{2} \mathrm{~N}_{1} \mathrm{~N}_{4}$
}

DOI: https://doi.org/10.36941/ajis-2021-0139

\section{Abstract}

The essay seeks to develop the foundations of a general hermeneutics, by which I mean a strategy of interpretation that not only encompasses the sciences and the humanities, but also seeks to integrate them. More specifically, certain classic texts in the humanities (i.e., those deemed representative of certain cultural traditions) are accordingly interpreted by way of categories derived from physics. In the present case, categories associated with quantum entanglement are applied to the classic or foundational humanities texts: Sophocles' Oedipus the King and the Old Testament Book of Job. The main categories brought to bear in this experiment in hermeneutics are the following: (1) entanglement itself, (2) locality-non-locality, (3) realism-non-realism, (4) latent and manifest levels of reality, and (5) internality-externality. After an introductory section defining the foregoing categories, the second section applies them to the texts in question with a view to redefining the relationship between two major components of the ancient world: the Greco-Roman and the Hebraic. The final section concludes the essay by outlining the framework of a general hermeneutics whereby schemas and objects of interpretation are structured in terms internality and externality. The former pertains to mind and culture while the latter is associated with a non-conscious materiality. Thus, four interpretive strategies can be deployed to give a comprehensive understanding of the world: (1) externalist schemas of interpretation applied to internalist objects of interpretation; (2) internalist schemas applied to externalist objects; (3) externalist schemas applied to externalist objects, and (4) internalist schemas applied to internalist objects.

Keywords: Entanglement, Hermeneutic Tool, Interpreting Text, Oedipus the King, Book of Job

\section{Introduction}

While 'entanglement' is a term used to describe a quantum phenomenon of the sub-atomic world, I am herewith putting forward the view that it can with profit be utilized to provide unexpected insights into two classic texts of the humanities: Sophocles' play, Oedipus the King and the Old Testament, Book of Job. These works were chosen because in my estimation they are representative of two major strands of the Western tradition - the Greco-Roman and Judaeo-Christian outlooks, especially as they pertain to the problem of suffering. They were also selected because, as I hope to show, they are particularly open to exploration by categories derived from the discipline of physics; 
and in that sense may illustrate a certain strategy for integrating what C.P. Snow termed the two cultures: the sciences and the humanities. Such integration may be thought of as a general hermeneutics or method of interpretation that encompasses both the sciences and the humanities. At a deeper level the hermeneutic integration at which I am aiming in this essay pertains to mind and body, where the long-standing Cartesian rift between consciousness and materiality may be reconsidered, if not reconciled.

\section{Methodological Considerations}

Because my integrative strategy is somewhat unusual, I will attempt to set the stage with a brief discussion of method. It is a method designed to achieve the goal of integration with respect to the insights of both the sciences and humanities, but it does not entail applying quantitative measurements to humanities subjects although this is not an illegitimate approach. Instead, my methodological goal is to determine if principles identified in the sciences are operative in a humanities context: philosophy, history, literature, etc. By the same token and in the spirit of symmetry, one could ask if the reverse were true, that is, if insights derived from the study of the humanities have a possible application to certain areas of the sciences.

While not all might take the goal of such integrative knowing as valuable or even possible, attempting to unearth such integrative principles tells us something about reality and may provide us with insights into the nature of the sciences and of the humanities that may contribute to their growth in the context of a mutual stimulation. Obviously, entanglement is not the only physics principle that may be applied to the humanities just as Sophocles and Job are not the only humanities texts to be explored with respect to principles derived from the sciences. In that sense there is an empirical aspect to this method insofar as it calls for collecting as many 'specimens' of successful application as possible. Should the collection be sufficiently large, one could apply to this body of material other forms of analysis to get a better handle on the nature of that sphere of reality where the sciences and humanities seem to infuse each other.

However, while my methodological goal might be empirical in spirit, the means are essentially hermeneutic and entail the interpretation of humanities texts by way of schemas of interpretation that are drawn from the sciences. In that sense my method may be described as part of a comprehensive hermeneutics with four basic frameworks of interpretation: (1) the application of scientific schemas of interpretation to humanities texts as objects of interpretation; (2) the application of humanities schemas of interpretation to objects of interpretation taken from the sciences; (3) the application of scientific schemas of interpretation to objects of interpretation taken from the sciences; and finally (4) the application of humanities schemas of interpretation to objects of interpretation associated with the humanities. The present discussion is centered on the first hermeneutic frame, but one can surmise that a complete understanding might entail the deployment of all four.

The hermeneutic aspect of this method, then, must center on the selection of schemas of interpretation, which I describe below as categories of analysis. Not only does my method call for their appropriate selection, but also for their tweaking in a manner that facilitates their application to the objects under investigation. 'Selection' and 'tweaking' may here be described as creative acts that interpreters can learn to perfect by ongoing practice. Application of such categories is perhaps no less creative and constitutes the core of this essay, the structure of which may broadly be outlined as follows: a discussion of categories of analysis (section \#4), application to the texts in question (section $\# 5$ ), a general conclusion as to future research directions (section \#6).

\section{A Necessary Proviso}

Before plunging into a discussion of categories, some of which might sound alarming to those having little familiarity with quantum theory and the entanglement phenomenon, let me say that my 
background is that of a student of the history of ideas and not that of a physicist. This point needs to be raised because it calls into question my capacity to understand, let alone competently apply, concepts that require many years of study at the university level. If I have learned anything by way of reading numerous 'popular' texts in physics, it is that there are no short-cuts to understanding. That being said, I am working on the principle that a category can prove its value on the basis of the insights it actually generates. Whatever my level of understanding may then be with respect to the phenomenon of entanglement in quantum physics, categories of analysis derived from that level may still be useful in enhancing our understanding of humanities texts even if those categories and my use of them are overly general or crude from the perspective of trained physicists. In any case, there is no gainsaying the fact that quantum entanglement is an important phenomenon; and as such its relationship to areas of knowing beyond those of physics is worth exploring. (Nadeau and Kafetos, The Non-Local Universe - The New Physics and Matters of the Mind, pp 198-218)

Moreover, one has to start this kind of journey somewhere, and it is not likely that quantum physicists themselves will undertake it by deploying their hard-won expertise in the direction of interpreting cultural trends. Indeed, they are likely to be averse to what I am attempting to do here since it seems to entail a kind of quantum 'mysticism' where scientifically subtle terms are being misused by intellectuals of various stripes who wish to appear more profound than they really are. With respect to my own intentions, I am not trying to appear more intellectually alluring by adorning myself with a thin drapery of quantum clothing. If what this essay is putting forward will make me the subject of mockery or contempt, so be it. Yet, if readers of various disciplinary backgrounds perceive a value in where I am going, then those with a deeper expertise than my own might open new venues of communication and create thereby a richer form of inter-disciplinary endeavor.

\section{Categories of Analysis}

Turning to the categories I will be framing for subsequent application, they are as follows: (1) entanglement itself, (2) realism, (3) locality, (4) latent and manifest levels of being, and finally (5) what I call internality and externality as fundamental dimensions of existence. As will be seen, these categories are, in a more colloquial sense of the word, 'entangled' with each other. That is, they will be shown to entail each other. However, it is important for the reader to understand that the first three definitions are only loosely derived from their formal use in quantum physics. Because they will be applied to classic texts in the humanities, their meaning has been broadened although hopefully not to the point that the following definitions have become completely unmoored from their foundation in the world explored by physics.

To start with the term entanglement, I take this concept to mean a relationship between two or more elements that come from a common source and are subsequently connected in such a way that interaction with one of these elements immediately affects the other despite a significant degree of separation between these elements. In the foregoing definition the separation can be spatial and/or temporal. To be clear, in quantum physics this kind of relationship has been experimentally demonstrated between quantum entities such as electrons and photons. Thus, entanglement is not a matter of theory, but something that takes place at a foundational level of reality, where entities like electrons and photons may be taken as underlying constituents of the physical world. In terms of everyday reality or the level of reality explicated by classical or Newtonian physics, such behavior is not apparent. If objects emerge from a common source, interactions with one of those objects should not and do not affect the other unless there is some signal that might co-ordinate the interaction between these separate objects.

Now by 'interaction' here, I mean the act of measurement by which physicists explore a given object or system of objects. Thus, electrons can be measured in terms of spin, which is an indication of its angular momentum and is either 'up' or 'down'; and while the deeper meanings of these two qualities need not concern us, from the perspective of entanglement if one of the two measurements is that of 'spin up', the other will invariably be 'spin down'. However, the word 'interaction' which 
figures in my definition was chosen because it is deliberately broader in scope than measurement and can thus apply to beings in the physical world and beings in the world explored by liberal arts disciplines. For example, if separation of beings takes place in a context of human interaction, then measurement may be more appropriately understood as judgment - a way by which humans 'measure' others in terms of such internal qualities as 'character' or personal identity.

With respect to measurement, what is called the 'orthodox' or Copenhagen interpretation of quantum theory makes a surprising and, from the perspective Einstein, shocking claim. (The claim was made by Danish physicist, Niels Bohr, one of the founders of quantum theory, and it is called the Copenhagen interpretation because that is where Bohr and a group of like-minded theorists developed this way of understanding measurement and the effect it has upon the existence of quantum entities.) The shock directly concerns the next term to be defined which is that of realism and juxtaposes realism to something that can only be called 'non-realism'. With respect to the latter, the Copenhagen interpretation states that until (and only until) an object is measured, it has no intrinsic reality or being. At best, that object has a potential to come into existence before it is actually measured. Hence, we define realism as a condition of an object whereby its existence has some form of being before it is measured (and thus is fundamentally independent of the act of measurement) and non-realism as an absence of some form of being until measurement takes place (and is thus dependent on the act of measurement).

For readers unfamiliar with quantum physics, this must come as a surprising aspect of the theory - perhaps more surprising than the entanglement phenomenon itself; and while there are other theories of how quantum measurement works, I am using the one just discussed in the subsequent analysis, not just because it is deemed 'orthodox', but also because it will be seen to have bearing on the world of human identity as articulated in the texts to be interpreted. Do humans have a well-defined identity before they are judged (i.e., measured) by other individuals or by beings who might be 'divine'? Counter-intuitive as non-realism may appear to be in the physical world, it appears to resonate well with certain fundamental cultural assumptions.

Moving on to our third category, locality, it too is linked to a kind of counterpart, which is nonlocality. Let us recall that if entanglement entails a correlation between elements that have emerged from some common source where those elements somehow interacted, and that the correlation seems to have no set of causal intermediaries accounting for it, then non-locality may be defined as that which expresses this apparent lack of causal connection. To put it simply, a causal connection usually entails the application of some direct force by one object upon another object to account for the latter's behavior. Locality then may be defined as a direct causal influence on a given object as opposed to a more mysterious non-causal influence as appears to take place in the phenomenon of entanglement. Furthermore, if the causal chain cannot be identified, then locality may still be operative if there are 'hidden variables' at work -- variables that may be said to account for the correlation of objects so distantly separated that any light signal could not be sent between them and thereby account for whatever correlations were being measured. Einstein's position on this centered on a belief that only such variables or hidden codes that defined the behavior of each measured quantum entity could account for the entanglement correlations. Until such variables were found, quantum theory, from his point of view, was incomplete. (Peat, pp.75-84) Again, while non-locality is as hard to accept as non-reality in the physical world (as we understand that world at an everyday level), we will see how it figures quite prominently in certain fundamental cultural assumptions that pertain to the human condition.

Turning next to our fourth category, latent and manifest levels of being, we are on much more familiar ground. The idea that reality can be layered is not strange to us at both the physical and psychological levels. By psychological I include cultural, and an obvious example is that of the Marxian distinction between sub- and superstructure, where the latter is comprised of the cultural rationalizations utilized to justify the former. The former layer is deeper or more fundamental because it refers to the basic property relations that can be used to account for the social dynamics and general patterns of historical evolution of a given society. At a personal level, the distinction was 
also drawn by Freud, where the psyche is basically layered with an unconscious instinct-based foundation (i.e., the id), over which a rationalizing and conscious ego seeks to hold sway with varying degrees of success. The point is that this layering is particularly evident at the level of quantum physics, which functions as a foundational aspect of being - an aspect that appears to be radically different from an upper level of being which functions according to a set of principles or rules that classical physics articulates and is familiar to us in the sense that this upper level is picturable even if we cannot directly see its actual functioning. The question that immediately comes to mind is whether the layering patterns at the physical level are comparable to the ones that exist at psychocultural level. If they are, then is there also a connection between the quantum nature of the latent level in physics and the latent level in culture? If so, what does this structural similarity tell us about the physical and the cultural? Is the world more inter-connected than might have been previously thought?

The last two questions take us directly to the fifth category set, that of the internal and the external. These are subtle terms, and they lead us to the heart of one of the most fundamental questions of human thought, which is the nature of thought itself or in more general terms 'consciousness'. (Rowlands, pp. 1-6) The literature on this subject is obviously too vast to recount here, but I am adopting these two terms because of the way they might entail each other in the manner of a yin-yang symbol, which may be said to represent the principle of complementarity. That is, I define internality-externality as a conjoined and complementary term where each of the two elements entails the existence of the other. Thus, internality is being associated with consciousness as an inner state of awareness that can only be fully understood by way of an implicit or explicit reference to that which is outside of that state. At a simpler level, the external is what one can perceive as the physical world; and if something is not perceivable as such, it is internalist in nature (e.g., thoughts, concepts, feelings, etc.).

I fully realize that these two dimensions of being and the conjoined definition I have provided are more of a rough sketch than a fully refined painting, but the broadness of scope that internalityexternality represents allows an interpreter of texts to look for complementary patterns in both dimensions of being (i.e., that of mind and culture on the one hand and that of matter and physicality on the other) and to assess whether these patterns are somehow recapitulated with respect to latentmanifest relationships associated with the fourth category. 'Complementary' here means mutually reflective or mutually entailing and may thus be contrasted with a reductive form of understanding where the internal can only be understood as a manifestation of the external. There might be other ways of understanding this most problematic of relationships, and reduction of the internal to the external in the context of neuroscience is an obvious approach. However, such a hermeneutic strategy downplays the internal as a dimension of being that may be profitably explored by a disciplined form of introspection.

\section{Applications}

For those unfamiliar with the two texts, the following outline may be useful. If I am ignoring cultural contextualization, it is because I am deliberately decontextualizing these works with a view to exploring how the categories developed in the preceding section can highlight significant differences in the two traditions from which they have arisen.

\subsection{Sophocles' Oedipus Rex}

The Sophoclean play is an outgrowth of a myth with which those in the audience were well familiar. A child born to the king and queen of Thebes, Laius and Jocasta, was the subject of a terrible prediction made by a seer. That is, the rulers of the city state were told that their newly born son was fated to kill his father and marry his mother. In order to avoid this terrible 'fate', Laius told a servant to abandon the child on a desolate mountain, and to make sure the child could not somehow crawl to 
safety, his ankles were pinioned together. Unfortunately, the servant took pity on the child and gave it to a fellow servant, who worked for the king and queen of Corinth. Thus, unbeknownst to the Theban rulers who presumed their son to be dead, the infant was given to the rulers of Corinth, who raised the child as their own and named him Oedipus, which means 'swollen foot' on account of his ankle wound.

As a young man, Oedipus was unaware that the chains of fate were beginning to tighten around him. It started when Oedipus heard, from a drunken man at some feast, that he might not be the son of his parents. Accordingly, he consulted an oracle to get some peace of mind on the question. However, when told by the oracle that he was fated to kill his father and marry his mother, Oedipus fled Corinth to avoid such a horrible future, for the oracle did not tell him that his Corinthian 'parents' were not his real father and mother. In his flight, Oedipus encountered an entourage of travellers who rudely pushed him out of the way. In a rage, he killed all but one of them. What he did not know was that the leader of the group was actually his true father and the man who escaped was the servant who was supposed to have left the child of Laius and Jocasta to die.

The road on which Oedipus was travelling led to the city of his birth, Thebes; but before he could reach that place, he met up with a predatory monster, a sphinx who killed people unable to answer her riddle. When Oedipus succeeded in answering the riddle, the monster, who had been destroying many Thebans, committed suicide; and Oedipus was hailed a hero by the inhabitants of the city. He was offered the kingship since the previous king had been killed, and the escaping servant claimed he and the rest of the royal entourage had been beset by thieves rather than by the new saviour of the city. Oedipus also married the king's widow, who, unbeknownst to him, was really his mother; and after a span of years wherein he had four children by her, a plague came upon the city. This is where Sophocles' play actually begins. Oedipus is bent on saving his city from a new source of suffering.

Oedipus learns, from an oracle consulted by his brother-in-law, Creon, that Thebes can only be saved if the killer of the previous king be found and punished by death or exile. Not knowing who the culprit may be, he consults another oracle, the blind seer, Tiresias, who is unwilling to help because he knows the truth. After much wrathful blustering, Oedipus gets the blind seer to talk; and when he hears what the man has to say, he assumes a conspiracy on the part of the blind seer and his brother-in-law, Creon. After an angry confrontation with Creon, Oedipus is convinced by the chorus and his wife, Jocasta, to take Creon's protestations of innocence as true. However, he starts to fall into doubt when he learns that the place of the previous king's death (where three roads meet) happens to be the very place where Oedipus had his murderous altercation many years ago; but because the escaping servant's story implicated a band of robbers, he asks for the servant to be brought to him so that his mind may be put at ease. While the servant is on his way, a messenger from Corinth arrives. He happens to be the man to whom the first servant gave the infant Oedipus, and he is here to tell Oedipus that the man whom he thinks to be his father is now dead and that the citizens of Corinth want Oedipus to return to be their king. While Oedipus is relieved to find out that he did not kill his 'father', he does not wish to return because his 'mother' is still living, and he fears marrying her. The messenger tells him not to be afraid because the queen of Corinth is not his real mother.

At this point Oedipus becomes obsessed with determining his true identity; and upon learning that the messenger gave the infant Oedipus to the Corinthian king and queen, he asks him from whom he got the child. At this climactic point, so rife with entanglement, the messenger says he got the child from the servant who witnessed and escaped from the scene of the crime wherein Laius was killed. Oedipus then begins to question the first servant, and in the course of this fateful interrogation he learns that it was he who gave the infant Oedipus to the messenger from Corinth so many years ago. He demands to know where the servant got the infant Oedipus. Although understandably reluctant to talk, the servant confesses that he got the child from its parents, Laius and Jocasta, with orders to abandon it because of the fearful prophesy. Out of pity he gave the child to the Corinthian servant in the hope that the prophesy would not transpire and that he would not 
have to let the child die of exposure.

Upon learning the terrible truth, Oedipus rushes into his palace to find His mother-wife dead by suicide (since she figured out before Oedipus what was going on and begged him, to no avail, to stop seeking his true identity). Oedipus, in an anguish of grief, puts out his own eyes with Jocasta's broach and comes before the citizens of Thebes as a broken man, ready to begin his exile.

\section{2}

The Old Testament 'Book of Job'

By contrast, the story of Job is not as complex as that of Oedipus although, as we shall see, elements of entanglement are clearly present in this Biblical text. Job is both a prosperous and upright man, but a fate of suffering is in store for him when God decides to let Satan torment Job in what appears to be a test of faith. After losing all his wealth, his children and finally his health, Job refuses to heed his wife's words, which are to curse God and die. (Job, 2,10)

Then, in the midst of his anguish, several friends come to comfort Job: Eliphaz of Teman, Bildad of Shuah, Zophar of Naamath and a younger man called Elihu, son of Barachel the Buzite. However, after an initial commiseration with Job, these 'friends' take a more judgmental tone that boils down to the following: because God is inherently good, wise, and just, Job must somehow have merited his suffering. Yet, in response to the 'truisms' of his friends, Job affirms his innocence. He knows that he has not done some evil deeds worthy of the punishment he is currently receiving at the hands of God; and if he has, he would like God to show him just how he has sinned. It is at this point that God speaks to Job; but instead of talking of Job's innocence or guilt, God poses to Job a set of unanswerable questions. These are not like the sphinxian riddle solved by Oedipus: what walks on four legs in the morning, two in afternoon and three in the evening? (The answer is a human being who in the morning of life crawls on four leg;, in the afternoon of adulthood walks on two legs; and in the evening of old age uses a 'third-leg' walking stick to supplement the other two.) No, the questions asked by God pertain to the very nature of existence and the mysteries of life. Job is not expected to answer the rhetorical questions posed by God because his human finitude precludes him from doing so. As such, Job repents of his presumption regarding God, whose wrath is kindled toward Job's friends who, in God's eyes, have not spoken what is true of the divine. God answers Job's prayers to spare them, and his fortunes are restored with interest. Unlike Oedipus, Job lives out the rest of his life in comfort and dies a respected man.

\subsection{Beginning the Application -- Entanglement}

With these two outlines giving us a basic sense of the texts, we can begin applying the categories of analysis defined above.

The first is, of course, entanglement itself, and it is not hard to see how this principle figures in the myth and the play. First, there is a separation from a common source. It is not a matter of electrons interacting with each other prior to separation. Entanglement transpires with respect to Oedipus and his birth parents. The procreation of Oedipus is the original interaction, but it is immediately followed by a separation based on the parents' reaction to the horrifying prophesy, that is, a separation ordered by the parents with a view to having their child killed by exposure. 'Measurement' in the form of a judgment takes place shortly thereafter as the servant charged with the deed takes pity (i.e., pity being am emotional form of judgment) on the child and decides to give the infant to another servant. In other words, this compassion-based judgmental act on the part of the servant can be contrastingly correlated with the fear-based judgmental act on the part of the parents. Not only are these measurement-like judgments curiously set in diametrical opposition to each other, those executing the judgments are at diametrically opposite ends of the social hierarchy: rulers with a relatively extreme level of freedom and a servant (who is actually a slave) with a relatively extreme level of unfreedom.

The result of these two measurements is an alteration of the state of the individuals separated 
from each other at a distant point in the past. The alteration is such that the individuals in question are in a state where they reflect each other in such a way that their respective behaviors are an odd combination of predictability and chance - a condition that parallels the way the quantum world seems to function. Although I lack the space to outline the connections between quantum predictability and randomness, these elements figure in the fatal encounter between Oedipus and Laius.

The state of mutual reflection with respect to father and son can be described as a condition of ignorance. In other words, ignorance is how their actual entanglement is manifested. The ignorance of Oedipus with respect to who he is and who his father is - this ignorance is entangled with the ignorance of Laius, who is ignorant of the fact that his son is alive and that the man whom he is striking with his goad as they meet on the roadway is indeed that son. Unlike the entanglement of photons, which is an external reality taking place in the physical world, the entanglement of human beings, at least in the world of myth, is an internal reality of mind. Moreover, the fact that entanglement can be predicted at the physical level is matched by the predictability of entanglement at the internal level of human interaction - a prediction made by certain gifted individuals called seers. Finally, the randomness aspect of quantum phenomena is matched by the chance-like quality of Oedipus encountering his father at a place where three roads met. In other words, the randomness is expressed by the possibility of Oedipus having been able to choose a different route. Nothing of a causal nature made him take the road that he did.

The foregoing deconstruction of entanglement for application to the human sphere of interaction sets the stage for yet a deeper level of entanglement that brings the play to its conclusion. Considerations of space preclude a detailed hermeneutic analysis, but the basic outlines can be sketched out to give a sense of how rich is Sophocles' articulation of the entanglement phenomenon. If ignorance is the background of one form of entanglement, knowledge is the key theme with respect to another form. That ignorance and knowledge are themselves entangled with each other as interconnected opposites suggests that the human search for truth (internal in nature) might itself be better understood from the external perspective of quantum physics.

The play itself is strongly structured around two forms of knowing - one being knowledge of those, like Oedipus, who are sighted and can use their understanding of the external world to solve riddles. The other is knowledge possessed by those who are blind to the external world, like the seer Tiresias, but are sighted with respect to the internal world where knowledge of underlying patterns seems to give them a different kind of insight. The fact that Tiresias either could not or would not solve the riddle of the sphinx - a point which Oedipus himself raises in his criticism of the capacities of the seer (p. 7o) - suggests that the two forms of knowing are separate from each other at the same time as they are connected as forms of truth, the knowledge of which can save a city like Thebes from a marauding sphinx and a devastating plague.

To be more specific, there is an anger-based separation between Oedipus and Tiresias at the outset of the play. Each makes a negative judgment of the other with respect to their ignorance; but when Oedipus gains knowledge of his ignorance toward the end of the play and blinds himself in a fit of anguished guilt, he also develops the inner insight of Tiresias - a point developed in a subsequent play, Oedipus at Colonus. Moreover, as a blind man, Oedipus is also entangled in a certain manner with the sphinx, whose riddle, solved by Oedipus, points to a final phase of life where a person walks on three legs. Since Oedipus is now blind in this new and final stage of his life, he will need to walk with a cane (or have someone function in that capacity for him). In other words, Oedipus has become the embodiment of the riddle he himself solved. However, the entanglement does not stop there. Just as the sphinx is a monstrous amalgamation of human and beast (head of a woman and body of a lion), Oedipus himself is a monstrous amalgamation of husband-son with respect to his mother as well as father and sibling with respect to the children he had by that mother.

To sum up this 'knowledge-ignorance' form of entanglement, we can say Oedipus' judgmental 'measurement' upon Tiresias has had an effect of a subsequent judgment upon himself - a judgment that precipitated his own blindness. If the 'sighted' Oedipus had shown more 'insight' into the words 
of the blind seer, Oedipus' judgment of himself might have been different and his behavior might not have led to the blindness that he inflicted upon himself. In other words, Oedipus' self-inflicted blindness expresses entanglement with a blind individual from whom he separated himself in an ignorance-based anger. Furthermore, the act of self-blinding expresses a connection to Tiresias from whom he separated himself - a connection associated with a new level of inner knowledge that Oedipus now possesses. What inner knowledge? The knowledge of his identity, of his inner being a knowledge which Freud connected to a deeper level of the internal, which is that of the unconscious. For Oedipus as a mythic figure may also symbolize the forbidden desires of a young man to possess his mother sexually and murder his father - desires located in the personal unconscious of certain individuals and entangled with specific kinds of neurotic behavior. The latter might control our lives like an alien fate until and unless they are brought under some measure of control by way of psychoanalytic knowledge. Even Sophocles hints at this deeper level of entanglement when he has Jocasta say to Oedipus: "Many a man before you, in his dreams, has shared his mother's bed." (p. 10o)

There is no need to hermeneutically rehearse more such entanglements in the play. The point of the exercise is to raise the question of whether entanglement might characterize the fundamental assumptions of that cultural configuration known as the Greco-Roman sphere and, beyond that, the ancient world in general (at least in its Western variant). But a tentative answer to that question requires us to see how entanglement fares with respect to a text drawn from another tradition - one that is played out in a more minor key and is associated in this essay with The Book of Job. After applying the entanglement category to that Hebraic text, we can turn to the question of how the realism and locality categories shed their light on the two sets of cultural assumptions articulated in these classics of Western thought.

Entanglement in The Book of Job has two main areas of operation: that between Job and God and that between Job and his friends. As with Oedipus, the theme of knowledge and ignorance plays an important role. With respect to the first of these, Job and God seem to have a special relationship - a relationship of which God appears to be proud. Thus, God says to Satan: "Did you notice my servant Job? There is no one like him on the earth: a sound and honest man who fears God and shuns evil." (Job, I,8) The separation of these entangled figures begins with Job's suffering. It is not so much a physical separation as it is a psycho-spiritual one, where Job feels a profound alienation from God although he refuses to 'curse God and die' (in the words of his wife). What Job does do, however, is focus on himself as one who has not done evil so as to merit punishment from God. This is where knowledge comes in as a kind of self-searching for the evil act that one might have committed. Job, of course, finds nothing. Yet, at the end of the text this form of knowing is entangled with ignorance - an ignorance that comes to light when God asks Job numerous questions about the mysteries of creation and Job comes up decidedly wanting in his ability to grasp its 'basics', let alone its intricacies. This is more than entanglement by opposition as when a 'spin up' measurement of an electron is balanced by a 'spin down' measurement of its distant partner. For is it not the case that to know oneself with depth entails knowing the limits of one's knowing? That sense of limitation is central to Job's entanglement with God: "I knew you [God] only by hearsay; but now, having seen you with my own eyes, I retract all I have said, and in dust and ashes I repent. (Job, 42, 56) To put it another way, Job's self-judgment is connected with God's judgment of Job's ignorance. Moreover, although the ignorance of Job pertains to the mysteries of creation, Job himself is part of the creation, and in that sense knowledge and ignorance are profoundly entangled with each other in the text.

With respect to the second area of entanglement, that between Job and his friends, matters are more straightforward. The initial commiseration of Job by his friends is the beginning of the entanglement. The separation occurs when these friends begin to judge Job harshly on the basis of their 'knowledge' of God's justice and goodness. On that basis, they assume that Job must be guilty of something; and, if he is unaware of his sin, Job must accordingly be ignorant This immediately affects Job's behavior as he angrily judges his friends to be ignorant rather than knowledgeable 
because they refuse to accept Job's own knowledge of his innocence. Behavior of a certain kind is characterized by each of the entangled parties taking the words of the other as essentially empty or lacking in knowledge.

At this stage of the argument we can note a major difference between the Oedipal and Jobian senses of entanglement - differences which I believe bear on important differences in culture. First, Oedipal entanglements seem to be caught up with a mysterious force called fate. Not only does it have an amoral and arbitrary quality - there is no reason for the fate to befall Oedipus or anyone else - it also has a curious omnipresence in the way it works. It manifests itself not only in the interactions of Oedipus and his parents, but also in the interactions of the two servants who are involved with saving Oedipus as well as, at the end of the play, dooming him. There is nothing like this in the story of Job, where the entanglements seem to have a simplicity and even a causal nature. God's comment about Job (caused by Job's exemplary behavior) is the occasion for Satan's challenging response to God. The rest seems to follow like a Newtonian clockwork. Secondly, while Oedipal entanglement is characterized by futile resistance to an impersonal fate which is more destructive than creative, the Jobian variant is characterized by the possibility of a personal reconciliation with a creative (divinely engineered) causal chain that was the occasion for the entanglement. In short, Greco-Roman entanglement bespeaks a lack of meaning while the Hebraic form offers the possibility of meaning through some kind of trust relationship with a personal creator.

\subsection{Application of Realism and Locality}

The forgoing qualitative aspects of entanglement can be clarified by the second and third categories: realism and locality. With respect to realism, let us recall that the term was framed as part of the orthodox or Copenhagen interpretation of quantum mechanics. It put forward the idea that a quantum object has no intrinsic nature until it is measured. (Nadeau and Kafetos, p. 37) Thus, it is non-real in comparison to a non-quantum object that has an existence independent of its being measured. To Einstein, such a position led to unacceptable consequences, such as the moon not being there unless one happens to be looking at it. (Is not looking a form of measurement?) At a deeper level, this may be associated with the idea of a meaningless world where things are essentially unreal and anything is thus possible. The human discourse known as science, which Einstein saw as a foundation of meaning, becomes pointless at worst and incomplete at best. As for locality, an object that is not real can hardly have a specified location. (Peat, pp. 105-108) If an event is arbitrarily connected, in what appears to be a non-causal manner, to an event extremely distant in time and space, then again anything is possible and the world takes on a quality of meaninglessness that must be stoically endured with dignity and courage. Stoicism is, of course, part of the Greco-Roman heritage, and one can see its appeal in the context of non-realism and non-locality.

In the two texts, realism and measurement are obviously not concerned with physical quantities. Measurement in Oedipus and Job is shifted to the human activity known as judgment and what is being 'measured' is the person, the self, of the two protagonists. With respect to realism, then, the contrast between the two selves could not be stronger. Just as there is a lesser degree of entanglement in Job, his person is also more real, that is, independent of judgment. Correspondingly, just as there appears to be a greater degree of entanglement in Oedipus, his person is less real, that is, more dependent on the judgment of others. To illustrate, Job is judged by his friends to be sinful at some hidden level. However, he does not bend to them. He judges his own self to be innocent despite their endless arguments to the contrary, and in that powerful sense he is independent of judgment and thus reflects a non-quantum realism. Oedipus, in his hyper-entangled world, has an identity that is totally caught up with the judgment of different parties including himself. Who is Oedipus? For that matter, who is anyone? It depends on when and who passes judgment. Is one and the same person four-legged, two-legged, and three-legged? In other words, is a person the same as an infant, an adult, and as an old person? As per the riddle of the sphinx, does judgment or 
measurement depend on the stage of life where one is judged (i.e., measured)?

Moreover, one may well ask what is the most important criterion by which a person is or should be ultimately judged? With respect to the two texts, is not the key criterion of judgment that of good and evil? Job, for example, implicitly judges himself as 'good' because there is no evil deed of which he is aware despite the negative judgments of his friends. Even when Job confronts God, the latter does not punish him for his presumption; and although Job judges himself as presumptuous after the encounter is over, that presumption is itself not a mark of evil inasmuch as God restores Job's fortunes. With respect to the goodness or evil of Oedipus, there seems to be no core identity because, although Oedipus did not commit his 'evil' deeds knowingly, he acts as if he did by taking full responsibility for murdering his father and marrying his mother. Unlike Job, then, he loses everything. Technically he could have assumed the kingship of Corinth, which was offered him, and save thereby the plague-ridden city of Thebes at the same time by leaving it. Is Oedipus not good at heart? Not in his own eyes. If he judges himself worthy of punishment, he must be evil, and his lack of evil intent means nothing in a world or culture characterized by non-realism with respect to the self. If this seems problematic to the modern reader, is it not because in the modern world we subscribe to a more Jobian sense of the self - a sense characterized by realism?

As for the third category, that of locality and its non-locality counterpart, one suspects that a greater degree of entanglement should be correlated with a greater degree of non-locality. Indeed, that seems to be the case with Oedipus in comparison to Job. But to bring this out, we must shift our frame from the externalist one of physics to a more internal one that has relevance to the humanities. If locality is a kind of relationship between objects where one directly impacts another by a known force, then non-locality is a relationship where there is no such causational force. In the first case, locality might still be preserved even if there is no visible force causing an interaction between separated particles if there is a hidden variable that is orchestrating the observed interaction. It may not yet be discovered, and it may never be discovered, but it must be there if locality is to be maintained as a way the universe works. In this regard Bell's theorem was used to prove that even hidden variables could not account for the degree of correlation that characterized an entangled system. (Nadeau and Kafetos, p. 74) Does that mean locality is disproven and that quantum entanglement is a non-localistic phenomenon? Obviously answering such a question is beyond the scope of the present essay, but the idea of a hidden variable (or hidden variables) does resonate with non-physical phenomena associated with human consciousness and its impact on physical reality.

As aspects of human consciousness, the non-physical phenomena to which I am here referring are acts of will or choice. If they are effective and manage to accomplish what an individual set out to do, then one can say conscious will and the choice that directed the will are local in nature. Why? Because the 'choice-will' complex has a direct and expected impact on the world. If it does not have that kind of impact and, indeed, has the opposite effect, then I would suggest that the complex is non-local in nature. To illustrate the non-local aspect of choice and will with respect to Oedipus, one can clearly see that although he chooses to evade his fate and seeks to do so by every power of his will (e.g., leaving Corinth to avoid the possibility of killing the man whom he thinks of as his father and of marrying the woman whom he thinks of as his mother), the results are not what he intended. Instead, the exact opposite happens, and he ends up killing his real father and marrying his real mother. In that sense his choice and will are not connected to the results intended, and thus, they are not local in a way that mirrors non-locality at a quantum level. The same is true with respect to the servant who sought to evade the negative fate that was to befall the child he was ordered to abandon. By choosing to give the child to a servant who was supposed to take the child far away, we have another example of choice and will not having the direct effect intended.

As for Job, at first it may seem that his righteous choices and the will by which he has executed them in his life have also led to the opposite result he was expecting because he is suffering as if he is being punished for unrighteous choices. Yet there is one great difference with respect to Oedipus one that fits in with locality - and that is a hidden variable. The variable in question is God (and to some extent his adversarial counterpart, Satan). Unlike fate or destiny, which are operative in the life 
of Oedipus in a mysterious and arbitrary way, the 'God' variable explains everything - the suffering at the hands of Satan, but also the entire fabric of reality which God reveals to an awe-struck Job at the end of the story. "Where were you when I laid the earth's foundations? Tell me since you are so well informed!" (Job, 38,4). God goes on and on revealing or intimating his direct influence on everything, and at the end, despite the vision of God's power, all Job knows is that the 'God variable' is there and that it must always remain hidden (thus dashing Einstein's hopes for a complete theory of reality). Why must the great variable of divinity remain forever hidden? Because humans lack the capacity to grasp it, and Job himself is forced to admit this: "I have been holding forth on matters I cannot understand, on marvels beyond me and my knowledge." (Job 42,3)

To conclude this part of the application of our categories of analysis, it would seem that just as non-realism and non-locality characterize the Oedipus text (and by implication the Greco-Roman tradition), so do realism and locality characterize the Job text (and by implication the Hebraic tradition). Obviously, I cannot review the two traditions which the texts represent in their own ways, but I can point out how utilizing terms taken from entanglement serves to resolve two mysteries within those texts - mysteries that are bound to challenge interpreters. The first concerns the matter of why Oedipus feels responsible for something he did accidently or unintentionally. The entanglement-based answer is non-realism. That is, because he has no fixed identity until he is judged (i.e., measured), Oedipus assumes the identity of a guilty person as soon as it is revealed that he did the deed. At a non-quantum level of reality, Oedipus would be absolved. At a quantum level of non-realism, he is damned. Similarly, on the basis of hidden variables at the quantum level, the meaning of God's silence about Job's suffering becomes understandable. Because God presents himself as the 'hidden' variable accounting for all things, the question of Job's guilt or innocence, not to mention the reason for his suffering, become effectively irrelevant. Whatever happens is because of God; and because the causal power of that variable is forever beyond human powers of understanding, that variable must remain forever hidden.

Forever? Because science can only advance by way of experimental proof and because that means a measure of control over the external world, we have reason in our time to question 'forever'. Surely there are no limits in our ability to control that dimension of being known as the external world and find those hidden variables that will give us new levels of power. Yet The Book of Job issues a dire warning in this respect. Before God concludes his speech to Job, he shows the latter a beast called 'Leviathan' (and before that another monster called 'Behemoth'). If it represents the external world and if science can only advance via experimental manipulation of that world, the beast may be interpreted as an ultimate limit: "Leviathan, too! Can you catch him with a fishhook or run a line around his tongue?" (Job, 40, 25-26) In other words, the more we plumb the depths of reality, the more we experience pushback, and instead of finding our way by science, we become, as one commentator has put it, 'lost in math' (Hossenfelder). The point is that because the Leviathan is the last thing that God reveals to Job, it may be thought of as foundational; and if foundational represents the deepest level of reality (apart from God), what is latent, then what is being represented by this monstrous metaphor is the intractability, the power, and the indifference of the deepest hidden variables with respect to the intentions of human beings and their futile desires to gain control of them.

\subsection{Application of the Layering Category}

In any case, the issue of the foundational takes us to the fourth category of analysis - the category associated with the layering of reality with respect to latent and manifest levels. With respect to physics, the quantum world underlies or is latent with respect to the world of everyday reality. The latter, studied by Newtonian or classical physics, is obviously manifest since it is built on the quantum level. More to the point, one can say that the manifest somehow emerged from the latent, and one of the ways that the former is distinguished from the latter is by the entanglement principles of non-realism and non-locality. Moreover, an absence of hidden variables marks the quantum level 
while their regular presence is a quality of the manifest level although some these 'hidden' variables can be identified.

How, then, might this latency-manifest structure apply to the two texts under investigation, not to mention the cultures associated therewith? If Oedipus and the mythic complex loosely associated with it can be identified with what historians call the ancient world (approximately 400o B.C.E to 400 C.E), is this world latent with respect to the more manifest Hebraic one? Although the Hebrew world extends almost as far back in time (approximately 2000 B.C.E.), it is not only radically different from those ancient world cultures surrounding it, but that difference may also be understood in two ways: (1) Hebraic culture emerged from the complex of other ancient cultures surrounding it; and (2) just as the world of classical physics emerged from the quantum one, its Hebrew counterpart has the classical qualities of locality and realism that are the mainstays of the everyday world as explicated by Newtonian principles. In other words, we can use entanglement as a hermeneutic tool to explore the Hebraic emergence as an 'upper' layer of a more foundational culture - one whose non-real and nonlocal entanglement structure bears a relationship to the quantum sphere. To be clear, one must not confuse the historical evolution of physics as a discipline with that of the historical evolution of the physical world. Quantum physics as an area of knowledge did 'follow' the classical physics of Newton, but the world of rocks and animals with their intricate structures did not precede the more elementary quantum elements of electrons, quarks, etc. Nor did the Hebrews generate the ancient cultures surrounding them. It was the other way around, and that evolution is significant insofar as it parallels a movement from a latent non-local and non-real cultural foundation to one that matches the locality and realism of a more manifest realm.

I am not here suggesting that the emergent culture is somehow more superficial with respect to its foundations. What I am suggesting is that the Hebrew emergence has a special role to play in advancing consciousness in the cultural sense and that the advance is characterized by locality and realism. I mention this because in physics depth or 'foundationality' is more highly valued than what appears within the purview of everyday experience. By contrast, in the world of the humanities, to the extent that growth as the realization of human potential is valued, the emergent may be more prized than the foundation. The point is that entanglement can function as a hermeneutic tool for bringing out this way of looking at the cultural phenomenon known as Judaism as well as the foundation known as the ancient world, from which Judaism emerged.

We are, of course, just beginning. A fully developed hermeneutic exploration of Judaism and the Greco-Roman world would entail a systematic application of entanglement categories to various aspects of these two cultural strands - strands that go far beyond the two texts I have used to launch this investigation. In other words, quantum non-locality and non-realism would be used to explore other aspects of the more latent Greco-Roman world just as non-quantum locality and realism would be systematically applied to the more manifest level of a particular ancient-world culture - a level I am identifying with Hebraic cultural assumptions. Moreover, just as cultural evolution did not start with the ancient world, it did not stop its evolution with the Hebrew emergence. Thus, if the ancient world itself emerged from more tribal, pre-literate cultures and if the Greco-Roman world gave way to Medieval 'Christendom', we must naturally ask if our hermeneutic strategy would encompass these broader phenomena of human cultural transformation. Finally, if entanglement categories should prove valuable in bringing multi-cultural phenomena (including non-Western forms) under one roof, we would also have to ask why they would be more successful than categories derived from the humanities.

This last question has bearing on the fifth category which is that of internality-externality. But before applying a category set that that addresses why categories derived from a study of the external world might have relevance to the internal world of mind and the cultural assumptions derived from human consciousness, we need to conclude our discussion of cultural layering by giving some salient examples of how non-locality and non-realism characterize the Greco-Roman world and how locality and realism characterize the Hebrew world.

With respect to locality, the Hebrews seem to have a non-local God in the sense that it is 
omnipresent, omniscient, omnipotent, and of course a kind of singularity or oneness that can be associated with monotheism. However, this non-local quality seems to have been significantly modified by an oddly localist emphasis. That is, the Hebrews have been chosen by this singular God and are thus distinguished from all the peoples of the earth. That quality of being specially chosen is marked by a law-like covenant, contract or testament that is endlessly refined as it is being interpreted - a process that continues to this very day. One of the laws forbids making an image of this God, who is approached less by sacrifices than by adopting an inner ethical attitude - an attitude that calls for valuing other human beings and treating them justly. One must also note that a key iteration of the covenant is its connection with freedom. That is, when led out of Egyptian slavery by Moses, the Hebrews were given a set of laws (the famous ten commandments) that Moses received from God on Mount Sinai - a set of laws that are thus implicitly associated with freedom. There is more to this crude sketch, but as an upper or manifest layer of culture, we are in a position to see how the qualities of locality and realism give this 'picture' meaning - a meaning that I suggest may be better appreciated through the application of entanglement categories.

Locality may be connected, not so much to an omnipresent God, but to God's mysterious act of choosing a specific people and interacting with them directly, not by a mysterious fate, but by a law that tells them what to do if they are to maintain their relationship with the divine and, by doing so, to also maintain their identity as a people. To clarify what the reader may take to be an excessive exercise of hermeneutic bravado on my part, let us recall that locality pertains to one entity directly affecting another in some form of causal interaction (e.g., a push, pull, signal) despite whatever distance may be separating them. Now God is as distant from humans as any manifestation of infinitude can be from any manifestation of the finite (the very point of the Job text). Yet, the interaction between these two parties is localized by a direct interaction with Moses being the mediating force that connects the Hebrews with their God. At a deeper level, the relationship is an embodiment of causality where God chooses to directly intervene in the lives of a specific people and, by that intervention, transform them in a way that separates them from all other peoples of the world. Moreover, it is a choice that is reflected on the part of the Hebrews themselves who, as Jews, can choose to accept or reject the choice made by God. Whatever they do, the emergent Hebraic culture is characterized by a localized causal relationship between the infinite and the finite.

With respect to realism, defined as an identity that precedes measurement, Hebrews who have chosen to accept their covenantal chosenness are given an enduring identity that withstands or is meant to withstand the 'judgmental measurements' or challenges of historical circumstance. With respect to the latter, God may be interpreted as a hidden variable in controlling history, and that hiddenness is emphasized in the context of the law by making God's name too holy to pronounce and by prohibiting the creation of physical images of the divine. More to the point, identity independent from the judgment of others is ultimately a measure of human freedom, and the fact that the law is bound up with freedom means that we are not arbitrarily controlled by non-local influences and, indeed, may build a society where such arbitrariness could be strongly mitigated.

It is the choice of each individual Jew to obey the law or not, and a key consequence of not obeying the law is a loss of identity - the main component of non-realism in the quantum sense. The law, in essence, is meant to free the Hebrew people from the suffering attendant upon non-realism. If realism can be understood as a well-defined identity, the commandments, which are framed with respect to such identity violations as killing and stealing, address themselves to respecting the identities of others and, in so doing, respecting one's own. Finally, if the last point suggests a level of entanglement inasmuch as one's freedom is interconnected with that of others, the potential arbitrariness of our choices is modified by that hidden variable known as God who co-ordinates the life of the entire community in the context of an original law-like chosenness.

Turning to the foundational level of culture (i.e., the one from which the Hebrews emerged), we have many variants from which to choose. If I am focussing on the Greco-Roman in general and the Roman in particular, it is because the latter was a kind of apogee of the ancient world - its high point, its yang-like maximum, before the transition to a Medieval Christian culture founded on different 
principles. The question confronting us is the following: whether or not late classical civilization embodies the entanglement principles associated with non-locality and non-realism? For if it does, then the Oedipus text, in having the structure that it does, may be interpreted as a reflection of that foundation and as part of the latency that I am associating with the ancient world.

At a very basic level the ancient world is built around what would be called a warrior culture, and Rome with its focus on military prowess is a prime example of this. But, in terms of 'identity realism', what is a 'warrior-hero' who represents the core values of ancient civilization? Is the warrior's identity as problematic as that of Oedipus? Since a warrior's life is defined by a struggle with some opponent, his identity is defined by the uncertainties of victory or defeat - a defeat that is associated with death or slavery. The former is a key focal point of Egyptian culture while the latter theoretically follows as an unwelcome option if the defeated warrior (and his descendants) is allowed to live in a state of subservience to the one who defeated him in battle and has accordingly choosen slavery rather than death.

What the foregoing sketch suggests is that identity in the foundational or latent warrior culture of the ancient world has no intrinsic 'reality' apart from the next life-death encounter. For that matter one cannot even know oneself to be truly happy until one's last moment since before that 'ending-time' anything could befall a person. For example, that 'anything' could be an untimely death or, if one is not a slave, moving into that miserable condition because of the instability of a culture beset with endless wars. Literary illustrations abound, but it would require more elaboration than would be possible within the confines of this discussion. Two that stand out because of their 'non-realism' associations with respect to radical identity shifts are Ovid's Metamorphoses and Lucius Apuleius' Golden Ass. The former is a set of stories which are connected by the theme of individuals being transformed, usually in the context of negative encounters with the gods. The latter is about the transformation of a human being into an ass and then back again. The first transformation is by way of a magic potion while the second concerns the power of the goddess, Isis, who is central to a Roman 'mystery-religion' cult. As part of cultural latency, these Roman classics contrast sharply with the what is emerging in the Hebrew worldview where identity is far more stable and thus embodies an emergent realism in the non-quantum sense (i.e., the sense associated with the classical physics of Newton).

A kind of historical climax occurs as these two cultures clashed in the Roman destruction of the Hebrew temple in Jerusalem (7o C.E.) - an act which is associated with the diaspora of the Jews. Locality is here emphasized as different groups of Jews left their erstwhile homeland and settled all over the empire in small and separate (i.e., local) communities. However, identity is maintained because of an internal hidden variable - God and/or God's plan. The external manifestation of this variable is the law or covenant, but even that is always being referred to as an inner attitude of ethical rectitude, to which the Hebrew prophets are always directing those who follow the external letter rather than the internal spirit of the law.

With respect to non-locality in the Roman context, one has to look no further than the empire itself - a structure that is inherently non-local inasmuch as what goes on in a distant community is entangled with what goes on at the centre. Otherwise, an empire is no empire, and Rome was far from being the only great imperial venture of the ancient world. In any case, an empire is a human construct no matter how it may be justified by texts that fashion an ideological-mythological glue meant to justify the conquest and control of distant lands. Thus, Vergil's Aeneid seeks to entangle Roman destiny with the Trojan war and the adventures of a mythical Trojan prince, Aeneas, as he seeks a new homeland, ultimately in Italy. His stop-over in Carthage and desertion of its queen, Dido, entangles the real historical struggles of Rome with a mythical past. Not only did Rome have to confront Carthage in a series of bloody wars, but Rome also conquered the Greek states in a kind of poetic revenge for the Greek destruction of Troy.

Given this non-locality that seems to characterize the latent foundation of the ancient world, we must contrast its external nature with the more internal locality of the emergent Hebrew culture. The latter is, as we have already suggested, rooted in its sense of being chosen by God, essentially 
internal in nature. The Hebrews were not chosen to rule the earth in the context of external domination although anti-Semites seem caught up with this idea. The Hebrews are supposed to be more of a moral exemplar - a condition which is burdensome and guilt-inspiring, to say the least. The Romans and other empire builders are more focussed on external power for the sake of order and the peace that is meant to follow from it, but somehow never does. The foundation of this perennial failure goes back to the non-realism of warrior identity. My sense here is that the insecurity attendant upon an identity that is not real, that is inherently unstable, may be symbolically (albeit inadequately) resolved by the establishment of empire, that is, of absolute external power that can only be absolute if it is universal.

Yet, apart from the dubious nature of this project, it may only be an addictive substitute for something that needs to be resolved at a deeper level - the level of non-realism associated with a warrior culture. For that resolution to occur, there must be a more penetrating awareness of the problem, and that requires an understanding of the meaning of history. At this point, I return to the basic theme of this discussion, namely that a deeper sense of meaning requires the application of categories of analysis that reveal those patterns which underlie our common journey through time. In the case of entanglement, my initial foray into understanding the latent-manifest structure of cultural evolution in the West has reached the following and very tentative conclusion: non-locality and non-realism reinforce each other at the latent level of ancient culture while locality and realism reinforce each other at the manifest or emergent level.

\subsection{The 'Internal-External' Category}

Having already utilized the fifth and final category of analysis in the foregoing application, we can bring this section of the essay to a conclusion by noting how the 'internal-external' schema of interpretation has hermeneutic significance with respect to mind or consciousness and its place in the world. To briefly review, the internal pertains to mind or consciousness, but in the present discussion the aspect of mind under investigation is not that of personal consciousness, but what I would call cultural consciousness, that is, those latent ideas that are fundamental with respect to a given culture. 'External' refers to ideas as well, but these are ideas directed to understanding the physical or material or apparently non-conscious aspects of being. To elaborate, the internal-external schema cannot escape a fundamental albeit inescapable ambiguity: the complementary terms are both internal since as concepts they are creature of the mind, but one of these -- the internal specifically refers to mind in and of itself while the other refers to what is not mind. The point is that the internal external category is of hermeneutic significance because of its foundational nature with respect to cultural discourse.

Such foundational ideas are, of course, a matter of interpretation, and I am attempting to orient my hermeneutic project by a creative juxtaposition of internal and external with respect to clarifying fundamental cultural assumptions. Thus, both Oedipus and Job were interpreted as particular embodiments of cultural assumptions that are foundational with respect to the Greco-Roman and Hebraic strands of the ancient world. Similarly, the foundations of the external world, as understood to-day, are embodied in the principles of quantum mechanics. These principles are also a set of underlying ideas, but their orientation to the functioning of the material world rather than to mind or culture per se makes them externalist in nature.

What is of interest is how the externalist quantum foundations of the physical world seem to mesh with the internalist cultural foundations of the ancient world. It is as if the hermeneutic journey to the foundations of latent reality bespeak an unexpected connection between the internal world of fundamental cultural assumptions and the external world of quantum reality - a connection that may be explored int terms of quantum phenomena other than those of entanglement as well as in terms of cultural phenomena other than those of the ancient world and western civilization. If the external world is matter-like or non-conscious while the internal world is mind-like or conscious, the structural connections toward which I have been pointing in this analysis present us with the 
possibility that mind and matter are not inherently separate but are intertwined in subtle ways. I would say the internal and external might therefore express the most foundational level of entanglement - a level that merits further exploration precisely because it ties internal and external together.

Can one then discover mind-like processes at the foundational level of matter, that is, the level of quantum entanglement? Can one find discover matter-like processes at the foundational level of mind, that is, the level of fundamental cultural assumptions? In short, do mind and matter mutually entail each other apart from what a more reductive hermeneutics might suggest - one where internality or mind is reduced to the externalities associated with brain function? The answer to these near-sphinxian riddles or 'Jobian' questions might only be revealed by way of employing inherently complementary categories such as internality and externality in place of less complementary categories such as those of mind and matter. In any case, I suspect that the more one probes, explores, and reveals the foundational levels of reality by way of the appropriate schemas of interpretation, the more one might find the entangled connections that characterize consciousness in its relation to what appears to be non-consciousness.

\section{Concluding Implications}

There is much that can be concluded from the foregoing analysis although one must admit that many, if not all, of these conclusions are necessarily tentative. While much more work would need to be done to solidify them, the concluding implications are not without significance in terms of their novelty and potential impact on the possibilities for developing a more integrative form of understanding the world. Indeed, the first implication follows from the preceding point. That is, the essay has endeavored to demonstrate the possibility that the humanities and sciences can be hermeneutically harnessed together to solve problems in original ways. What problems? There are at least three sets: those of the humanities, those of the sciences, and those pertaining to the relationship between the humanities and the sciences.

With respect to the first set, I have sought to identify fundamental problems with respect to interpreting classic texts: the fact of Oedipus taking full responsibility for something he did inadvertently and God's silence with respect to the reason for Job's suffering. Using terms derived from the externalist sphere of quantum entanglement, I attempted to provide a kind of solution to these internalist or mind-like problems. Moreover, I extended these solutions to the relationship between two fundamental strands within the ancient world: the Greco-Roman and Hebraic, and how the latter emerged from the former in a manner that parallels how local and realist levels of reality emerge from the non-local and non-real quantum foundation.

With respect to the set of problems associated more with the scientific world, my discussion attempted to shed a new light on the interpretation of quantum reality. The Einstein-Bohr debate on the nature of reality can be re-considered not simply via the way Bell's theorem favors resolution with respect to Bohr's position, but also by contextualizing that debate as part of a much larger intellectual framework - a framework that has not been recognized up to now. Here I am referring to how physics is not the only area of intellectual endeavor to be structured around the question of local realism. For example, I believe it can be shown that Freud was local and realist (with his emphasis on a personal unconscious) in comparison to Jung, who was non-local and non-realist (with his emphasis on a collective unconscious), and that this tension-like pattern may well encompass other disciplinary spheres: Husserl and Heidegger in philosophy, Marx and Hayek in economics, and Judaism and Christianity in religion. Obviously, I cannot go into detail, but debates in physics might be seen in a new light if they can be contextualized in the broader framework I am outlining and inviting other readers to explore. Could such contextualization transform or alter debates in physics (let alone other sciences)? I cannot at this point say. However, I cannot help but notice that that Judaic backgrounds of the first figure in each pair is matched by the 'gentile' background of the second party to the debate. A tantalizing perspective on intellectual conflict is being put forward by 
this observation. I doubt it is a coincidence that Einstein, Freud, Husserl, and Marx are together in local and realist ways of thinking and thus look forward to elaborating on this pattern in future discussions.

Finally, with respect to implications relating to the problem of interconnecting the sciences and the humanities, this essay is based on the view that if the internal world associated with the humanities has its own integrity and is not to be viewed as something purely derivative from an externalist reality as studied by the hard sciences, then the best way to approach the internal with a view to discovering its treasures and insights is nothing less than introspection - Carlo Rovelli's dark reservations on the value of introspection notwithstanding (Rovelli, p. 186). Indeed, this essay is built on the principle that introspection can work hand in hand with its natural partner, which I would call extrospection, the most foundational form of which is, of course, physics. How might introspection and extrospection be jointly harnessed? By developing an introspective method that is as disciplined in its own way as is physics. That means creating a general hermeneutics that includes all possibilities of interpretation and involves hermeneutic strategies that are applied in a systematic manner.

In this essay I have applied externalist categories which were foundational (categories that pertained to quantum entanglement) to internalist categories that were also foundational in the cultural sense (classic texts). Furthermore, I went in the other direction and applied internal categories of 'judgment' and 'will' to explore externalist categories of realism and locality with a view to seeing them in a new light. Whether or not anything of value can follow from this lies in the hands of those with a much more adequate level of expertise in physics. In any case, there are only two other hermeneutic strategies: applying externalist categories to externalist objects of interpretation and applying internalist categories to internalist objects of interpretation. The former is the sphere of science while the latter may be associated with religious or spiritual forms of knowing. In short, the four hermeneutic strategies not only attempt to restore introspection to a place of respect in the world of knowledge, they open the door to a more comprehensive way of knowing as well as offering a certain perspective on how intellectual disputes may be resolved in creative ways. Instead of acrimonious 'dead ends', we might be able to fashion a 'living means' to reach deeper truths.

Perhaps I have tried to achieve too much in this essay and placed inappropriate burdens on my readers. What I am putting forward as a kind of project is really the task of many individuals working together in a new kind of intellectual framework. It is a framework that might have to take form in the space of a new institute, which I would call the 'Institute of Hermeneutic Studies'. It is a title I have chosen because of the significance of its initials, IHS -- initials which are associated with the vision that came to Constantine before his conversion to Christianity. In Latin it stands for 'In hoc signo': in this sign. (For Constantine the sign was that of the cross.) What follows is the word, 'vinces', which means 'you shall conquer'. An institute of hermeneutic studies that brings together under one intellectual roof the four strands of a complete hermeneutics might indeed entail conquest. Conquest of what? Of the fragmentation and fruitless disputation that often hinder the most creative kind of truth-seeking.

\section{References}

Apuleius, L., (1994). The Golden Ass. Trans. P.G. Walsh. Oxford: Clarendon Press.

“The Book of Job," The Jerusalem Bible - Reader's Edition. Garden City, NY: Doubleday and Company,1968

Brady, J., (2020). Quantum Entanglement. Cambridge, MA: The MIT Press.

Hossenfelder, S., (2018). Lost In Math - How Beauty Leads Physics Astray. New York: Basic Books.

Nadeau, R., \& Kafetos, M., (1999). The Non-Local Universe - The New Physics and Matters of the Mind. Oxford: Oxford University Press.

Ovid, (2004). Metamorphoses. Trans. David Raeburn. London: Penguin Books.

Peat, F. D., (1990). Einstein's Moon - Bell's Theorem and the Curious Quest for Quantum Reality. Chicago: Contemporary Books. 
Rovelli, C., (2021). Helgoland - Making Sense of the Quantum Revolution. Trans. Erica Segre and Simon Carnell. New York: Riverhead Books.

Rowlands, M., (2003). Externalism - Putting Mind and World Back Together Again. Montreal: McGill-Queen's University Press.

Snow, C.P., (1980) “The Two Cultures," Reprinted by permission of Cambridge University Press in Classics of Western Thought, Vol IV, The Twentieth Century. Edited by Donald S. Gochberg. Fort Worth: Harcourt Brace Jovanovich.

Sophocles, (1988). "Oedipus the King” from The Three Theban Plays. Trans. Robert Fagles (1982). Reprinted by permission of Viking Press in Classics of Western Thought, Vol. I, The Ancient World. Edited by Donald S. Gochberg. Boston: Wadsworth, Cenage Learning.

Virgil. Aeneid. Trans. Allen Mandelbaum. New York: Bantam, 1981 